Ljubinko M. Pušić

UDC 316.334.56

Filozofski fakultet Univerziteta u Novom Sadu

$711.4: 316$

pusic@eunet.rs

$316.334 .2 / .3(497.11)$

316.4.(497.11)

Originalan naučni rad

\title{
PRAKSA TRANZICIJSKIH PROCESA U SRBIJI KAO KULTURA ANTIURBANOSTI
}

Bar u poslednje dve decenije, pokazuje se da se Srbija nalazi na jednom antimodernizacijskom putu. Nepostojanje jasnog društvenog koncepta koji bi doveo do moderne, demokratske i građanske države može se dokumentovati i pratiti na veoma različitim nivoima. $U$ radu se razmatraju uzroci i posledice nekoliko dominantnih antiurbanih procesa, koji predstavljaju praksu njenog potonjeg tranzicionog puta; na prvom mestu urbanizacije. Takođe se razmatraju i delatne mogućnosti dihotomija ruralno-urbano, kao susret dva kulturna obrasca. Teorijska i praktična platforma na kojoj počiva rad temelji se na stavu da se kultura antiurbanosti javlja kao praksa tranzicijskih procesa u Srbiji.

Ključne reči: grad, urbanost, kultura, tranzicija, urbanizacija.

$* * *$

Početak ovog veka nedvosmisleno je pokazao da je budućnost u kojoj će ekumena definitivno biti urbana, već počela. Kada smo pre više od decenije napisali da je bavljenje gradom postala neka vrsta mode $u$ intelektualnim vežbanjima, nije se moglo pretpostaviti do koje mere će ta vrsta zanimanja za grad postati sveraširena. Dugo je to bila samo naznaka jednog obnovljenog diskursa, sasvim nezavisno od pojedinačnih naučnih disciplina i traženja novih prostora za istraživanja. Grad se, po ko zna koji put u svom petmilenijumskom trajanju, našao na neobilaznom mestu u pokušajima da se objasne složeno i snažno isprepletane mreže društvene stvarnosti. Koliko do juče grad je, pre nego istraživačko i naučno polje, predstavljao predložak za literarno viđenje sveta, mesto gde se reprezentovala društvena dinamika; gde su se nalazile "velike teme". Ovim temama nisu odoleli književnici ili oni koji sebe tako 
vide, zatim oni koji idu za njima i kupe mrvice književnosti uobličavajući ih u kritiku, ali ni mnogi drugi poslenici u društvenim i humanističkim naukama kojima je trebalo „neko“, naizgled prihvatljivo objašnjenje za one teze kojih su se dohvatili. Grad, ta čarobna reč; alibi i objašnjenje za sve što se događa u svetu koji sve manje razumemo. Grad kao uzrok i posledica svih ovosvetskih pošasti, romantičarska inspiracija, ogledalo racionalnosti, psihološka laboratorija, tehnotopijska vežbaonica, grotlo multikulturalnosti, zamajac globalizacije, glavni remetilac klimatskih promena na planeti. Jednom rečju - paradigma neodrživog razvoja civilizacije kojoj pripadamo. Istovremeno, grad je najvrednije postignuće iste te civilizacije. Grad kao društvena konstrukcija i nesumnjiva stvarnost koju istovremeno podupiru eros i tanatos. Nešto poput drvenog gvožđa; a opet, postoji! Upravo zbog svoje magijske privlačnosti danas ima previše onih koji misle da je bavljenje gradom nešto poput pasije, gotovo hobija; grad je, čini im se, upravo ono što im je donedavno nedostajalo da bi bili moderni!

Pretenzije da književnost u svojim recepcijama i prezentacijama grada $\mathrm{i}$ gradskog može da zameni urbanologiju upravo su odraz nerazumevanja da grad može da bude i nešto više od naracije ili samo "predmeta naučnog bavljenja". To što grad mogu da čitaju i da ga ispisuju Igo, Derida, Fuko, Dučić, Crnjanski, Selenić ili Pekić, na primer, ne znače da se oni bave gradom kao društvenim fenomenom, već se samo da ih u jednom trenutku, u jednom ili nekoliko dela, grad svojom fenomenologijom zaokuplja. U nekom drugom trenutku, njihovo interesovanje biće na nekoj sasvim drugoj strani.

Još ima onih koji, kao da je F. Engels pisao juče, veruju da se grad i selo nalaze na krajevima svakovrsnih društvenih suprotnosti. Teza o dijalektičkom suprotstavljanju grada i sela definitivno je smeštena u arhivu društvenih ideja. Ona se, međutim, izvlači na svetlost dana uvek kada je oportuno instistiranje o „dva sveta“, o dihotomijama kojima treba da se pojasne pojedini društveni procesi kojima se tumače društveni nesporazumi. Pre nego što se može govoriti o društvenim odlikama „dva sveta“, ruralnog i urbanog, treba imati na umu kako se radi o stanju svesti. Premda su razlike u atribuciji ruralnog i urbanog u Srbiji još uvek snažno vidljive, mi radije govorimo o stanju svesti koju proizvodi jedna ili druga socioekološka sredina. Pri tome, vrednosno ne određujemo ni jedan elemenat socioekološkog porekla ruralnog ili urbanog, nego govorimo o stanju svesti. 
Vladajuće dihotomije koje podrazumevaju podelu ukupnog društvenog života na urbano i ruralno delovi su ne samo tradicionalnih već i sasvim novih društvenih podela. Dovoljno je samo upustiti se u analizu postpetooktobarskih događaja iz 2000-te godine u nas, pa da se ove linije razgraničenja jasnije ukažu. Poznato je da je stanovništvo u tom vremenu i datim okolnostima imalo mogućnost vrlo suženog izbora i šansi za preoblikovanjem sopstvene prošlosti. Zapravo, postojale su svega dve mogućnosti. Jedna je bila proevropska, druga nacionalno-nacionalistička. Uz mnoge druge sadržaje kojima bi se dale opisati unutrašnje društvene dihotomije, jedna je bila i ona o urbanom i ruralnom društvu. Po definiciji koju niko nije obrazlagao, jer se ona valjda podrazumevala, nacionalno-nacionalistički blok imao je predznak ruralnog a onaj proevropski predznak urbanih stremljenja. Jasno je da je ovakvo pojednostavljivanje, koje svakako nema uporište u stvarnosti, moglo da proizvede i mnoge druge podele. Zapravo, one su postale i deo obeležja političkog života koji građani Srbije danas proživljavaju. „Nažalost diferenciranje na evropske i antievropske sile obuhvata ne samo političke stranke, medije, organizacije nego i same ljude. Ova dihotomija služi i hijerarhizovanju ljudi po njihovim kulturnim karakteristikama. Niži nivoi uspostavljenih hijerarhija postali su objekt ponižavanja, obezvređivanja, represije, diskvalifikovanja. U ovim procesima se manifestuje kolektivna agresivnost i mehanizam projekcije“ (Štrbac 2009: 3).

Sa druge strane, slabost dihotomijskog pristupa u tumačenjima društvenih pojava, pogotovo u političkom diskursu, je i u tome što se one često koriste kao svojevrsni alibi za stigmatizaciju „onih drugih“. Ali, mogući su i drugačiji pristupi, odnosno da se dihotomijama odrekne validnost. U takvim pokušajima moguće je da se i dihotomije urbanog i ruralnog proglase anahronim. Ovo je moguće samo u onom svetu mišljenja gde se grad ili "filozofira" ili "književno konstruiše" ili pak tada kad se posmatra isključivo u svojoj geografskoj datosti i materijalnoj stvarnosti. Nalazimo da je u oba ova slučaja postmodernih gradonavada reč o suštinskom nerazumevanju onoga što grad jeste.

Ljudi obično u gradovima koji predstavljaju deo njihovog sopstvenog iskustva vide mane i vrline koje potom pokušavaju da transponuju na jedan semantički nivo. Njihovi pokušaji poređenja sa drugim sredinama i uopštavanje sopstvenog iskustva tu negde počinju. To svakako nije novo otkriće, ali objašnjava zbog čega su ljudi oduvek posezali za dihotomijama koje se kreću na ravni prošlost-sadašnjost, sadašnjost- 
budućnost ili prošlost-budućnost. Konačno, da nije tako, ne bismo bili bogatiji za sve one utopijske ideje i projekte tokom bar poslednja tri milenijuma urbane istorije. Tačno je da su neki utopijski projekti, poput progresizma, na primer, prestali to da budu kad su iz napisanih i nacrtanih fantazmi prešli u stvarnost od koje više ne može da se pobegne; sem u neku drugu utopiju. Da bi se zamišljali gradovi, te da bi bilo moguće da se vidi šta stoji iza horizonta rasprskavanja gradskog i prelaska u urbano, potrebno je primarno urbano iskustvo. ${ }^{1}$ Ovog puta svesno nismo odabrali pravac koji nas vodi preko istorijskih značenja urbanog, premda nam je prilikom mnogih čitanja i pisanja grada to bio put kojim smo rado išli. Taj, često zapreten, ali gotovo uvek zavodljiv put u razumevanju savremenih značenja i pojmova urbanog, odveo bi nas sve do antičkog polisa ili do pojedinih etapa u razvoju evropskih, odnosno zapadnih društava već od 18. veka. Sem što je taj put manje-više poznat svim odgonetačima urbanih procesa, na njemu se ne nalaze baš najsigurniji pokazatelji o neurbanom stanju u Srbiji na pragu 21. veka. Mada, kad god bacimo pogled na istoriju ideja koje su uobličavale društvenu misao sred koje se nalazio grad, videćemo da paralele sa savremenim nisu stvar naše nemogućnosti da se odvojimo od istorije, već nemogućnosti da stvarnost bude na suprotnom kraju istorije. Konačno, to nije uspelo ni utopijskim projektima, svejedno da li su oni bili filozofske, sociološke, kulturno-istorijske ili književne prirode. Kada Fihte kaže da „cvetanje grada beše uništeno tiranijom i pohlepom prinčeva (...) pogaženom slobodom“ (Šorske 2008), tad bi parafraza u odnosu na aktuelno srpsko društvo mogla da bude: Mogućnosti da se nastave procesi prekinutog puta u građansko društvo tokom gotovo celokupne druge polovine 20. veka, upravo su poništene „nemoralnom državom“ koja je stupila na scenu odlaskom autoritarnog režima u oktobru 2000. godine. Kada je jedan nemoralan režim voljom naroda otišao u istoriju, na scenu je, zahvaljujući onima koji su se domogli vlasti a koji državom nisu umeli da upravljaju na način da je prevedu u demokratski društveni poredak, sistem postao još nemoralniji! Naši gradovi najjasnija su slika i mera te nemoralnosti.

Procesi stasavanja modernih urbanih društava zapadne provenijencije i onog što se u smislu društvene organizacije događa u Srbiji tokom druge polovine 20. i u prvoj dekadi 21. veka, prilično su udaljeni. Pokušaji da se potonja praksa objasni

1 Premda bi po prirodi stvari bilo logično da su nam ideje o vizijama urbane budućnosti, a koje počinju i nastavljaju se na ovim prostorima - bliže, slutim da je malo onih koji su o tome razmišljali onako kako nam to, na primer, predstavlja Ivo Tartalja u knjizi Beograd XXI veka (SKZ, Beograd, 1989.). 
procesima dugog trajanja koji su uvek na snazi kada je reč o tranzicionim društvenim procesima, u srpskom slučaju poslužila su kao alibi za kleptokratsku praksu koja je nezabeležena u modernoj Evropi. Ne tako davno napisali smo da su srpski gradovi poput kradene robe, verujući da je to stanje privremenosti koje će se, uobličavanjem demokratskih procesa, ako ne sankcionisati a ono preći u istoriju (Pušić 2005). Danas znamo da nismo bili u pravu i da je po svoj prilici na delu proces dugog trajanja; trajanja bar dotle dok iz gradova ima još nešto da se proda zarad ličnih i grupnih interesa vladajućih nomenklatura.

Ono bez čega nije moguće razumeti dimenzije urbane kulture, pogotovo $\mathrm{u}$ njenim ekstremima koji se manifestuju u diskursu dihotomija koje prelaze u apologije, jeste viđenje grada kao epicentra iz kog se razara društvo. Kultura antiurbanosti kao praksa tranzicijskih procesa u Srbiji jednim svojim značajnim delom utemeljuje se i u nemogućnostima posednika vlasti da kontrolišu i upravljaju društvom, stvarajući preduslove za pristojan život u naseljima. Budući da njihovo osvajanje gradova podrazumeva tolerisanje, podsticanje i istovremenu proizvodnju vrednosti nemoralnog društva (kleptokratija partijskih posednika lokalne vlasti, nepotizam, korupcija, spregnutost sa „kontroverznim poslovima“, funkcionalno demontiranje institucija, itd.), urbana supstanca društva se iscrpljuje. Iako istorijsko iskustvo poznaje ovakvu praksu, moderna građanska društva nikad ne bi postala pristojna društva, bar ne onakva kako je o njima pisao A. Margalit (Margalit 1989). Grad kao pakao na zemlji tema je koja je starija od hrišćanskog verovanja u mogućnosti podele sveta na njegove mane i vrline.

Kao što definisanje grada ne podleže naučnom konsenzusu, tako ni u slučaju urbane patologije nije moguće ustvrditi kako je grad sam po sebi okrilje mnoštva patoloških pojava. Tako nešto ne predstavlja realan ugao posmatranja ni sociologije niti bilo koje druge društvene nauke, što se pre objašnjava dinamičkom prirodom samog fenomena nego različitošću interesovanja. „Tako, na primer, između poimanja grada dva filozofa, Aristotela i Ničea, stoji prividan nesporazum. Prvi će reći da se u grad dolazi da bi se živelo boljim životom. Budući da se radi o grčkom polisu, sred kojeg Aristotel i oblikuje svoju misao, razumevamo kako se ovakvo ushićenje moglo odnositi samo na polis i na pripadajuće vreme. Kada, pak, Ničeov Zaratustra izgovara da je "u gradovima (...) loše živeti: tu ima odveć mnogo ološa", tada mi znamo da se radi o filozofovom doživljavanju grada sa iskustvom savremenih tekovina industrijske 
civilizacije. Konkretno empirijsko iskustvo oduvek je oblikovalo vrednosti kojima se karakteriše grad, isto kao što je uslovljavalo nova idejna, najčešće utopijska stremljenja. Razumevamo li istorijski kontekst formiranja misli o gradu, biće nam jasno da je svaki od njih u pravu. To znači da istorijski posmatrano nema univerzalne definicije grada. Kao što nema ni mesta prostom izjednačavanju pojmova grada i civilizacije. Pokušajima za univerzalizacijom značenja, kako postupa filozofija, suprotstavlja se razumevanje u kontekstu, na čemu insistira sociologija" (Pušić 1997: $30)$.

Međutim, srpska urbana stvarnost kao da je ponovo načela priče o gradu kao epicentru svih društvenih pošasti. Drugim rečima, kao da je na delu povratak u predmoderno vreme. Za opisivanje svakodnevice srpskih gradova danas više nije potrebno iskusno analitičko oko jer ju je u svojim neurbanim manifestacijama nemoguće prevideti. Celokupna politika koja je stupila na scenu sa objavljenom tranzicijom i još više nakon privida oslobađanja od nedemokratske prošlosti na samom početku ovog veka, usredsređena je na osvajanje gradova. Tamo se nalazi sve ono što je toliko puta opisivano u urbano-sociološkoj literaturi: poluge ekonomske moći, odnosno novac. Upravljanje gradovima danas se pridružilo celini onakve društvene neodgovornosti koja je očevidna u upravljanju svim sistemskim institucijama kod nas: obrazovanju, sudustvu, zdravstvu, bankarskom sistemu... Potpuno zatomljena strategija prostornih, političkih i administrativnih strategija (koje bi trebalo da su sinhronizovane) dovela je do haotičnog rasporeda gradskih centara. Na teritoriji Srbije oni su još uvek odraz političkih a ne racionalnih interesa. Njihov prostorni raspored (ukupno 23 grada u Srbiji) nalikuje mapi objekata kakvog trgovačkog lanca. Gradovi kao dragstori u kojima se novcem u neograničenim količinama snabdevaju posednici aktuelne vlasti, predstavlja samu armaturu društveno neodgovorne i antiurbane politike. Ovakva urbana scenografija kao prirodni svoj deo sadži i sve poznate oblike društvene patologije: apsolutnu vladavinu 'belih okovratnika', korupciju, kleptokratiju, nepotizam, vrhunjenje „ljudi koji su se snašli“ u vrtlozima tranzicije, narko-dragstore, urbanu, urbanističku i građevinsku mafiju... Na drugoj strani je ogledalo ovakvog činjenja: moralni sunovrat države, oprostačena svakodnevica i poraženo građansko društvo. 
Gotovo celokupan „scenario“ srpskog potonuća u neurbano društvo ispisuje nekoliko paradigmi: urbanizacija, industrijalizacija, modernizacija, demokratija i kultura. Jasno da su one međusobno isprepletane, međuzavisne, odnosno da se ne mogu posmatrati isključivo pojedinačno.

Veze između tranzicije i stvaranja obrazaca urbane kulture u poslednjih dvadeset godina višestruke su i složene. Mnoge društveno relevantne pojave mogu se posmatrati i kroz paradigmu tranzicije (kako je to u mnogim dosadašnjim istraživanjima i činjeno). One čak ne moraju obavezno da predstavljaju rezultate strogo naučno podešene istraživačke prizme, s obzirom da je reč o očevidnostima svakidašnjeg života. Analizirajući pojedine oblike tranzicionog pozicioniranja pojedinaca i društvenih slojeva, moguće je uočiti i neke sličnosti sa vremenima za koja smo verovali da su daleko iza nas. Onima koji su iz Drugog svetskog rata izašli kao pobednici a pri tome su pripadali makar i najmanjem delu vladajućeg establišmenta, jednako kao i onima koji su u potonjoj tranziciji videli mogućnost za promociju sopstvenog prosperiteta, gradovi su se ukazali kao nezamenljiva društvena scenografija. I to ne makakvi gradovi, već oni najveći. Kao što znamo, u Srbiji ih i nema baš mnogo, te je njihova pozicija u novotranzicijskom osvajanju odgovarala njihovoj populacionoj veličini. Naporedo sa ovom, inače vrlo heterogenom grupom, na samom kraju prošlog veka u osvajanje gradova pošao je i najveći broj onih koji su, nošeni neprilikama u ratnom okruženju, svoju perspektivu potražili u Srbiji. Ali ne bilo gde, već upravo i ponovo u većim gradovima. O tome sasvim rečito govore podaci o strukturi populacionog porasta, posebno Beograda i Novog Sada od devedesetih godina prošlog veka. Mnogi su došavši u nove gradove za sobom ostavili teskobu malovaroških sredina, a za nemali broj novourbanita to je predstavljalo sasvim novo iskustvo. Njihove ponete kulturne vrednosti bile su bez primarnog urbanog sadržaja, ali kada su osetili gradsku slobodu, nije im više smetao ni gradski smog. Tu slobodu doživeli su poput duhovne infuzije i bez nje više nisu mogli. A naši gradovi su mogli bez njih dok su se sa njima pre približili naseljima iz nerazvijenog sveta, gde predurbaniti čine glavni supstrat hiperurbanizacije.

Jedan od bitnih problema urbane kulture nastaje upravo zbog nespremnosti, ali i objektivne nemogućnosti, novourbanita da prihvate i kvalitativno nadograde zatečene urbane vrednosti. Razume se, pri tome nikako se ne može tvrditi da su 
one vrednosti koje su zatečene autentično urbane, da obavezno imaju pozitivan predznak, te da predstavljaju i eventualno „bolji par“ u dihotomnim prikazima ruralnih, odnosno urbanih vrednosti. Bilo bi analitički nedopustivo kada bismo se zaustavili samo na ove dve vrste novourbanita. Svakome ko se bavi gradom jasno je da bez dobro pripremljene društvene podloge ni jedna pojava u gradu ne uspeva. Da su naši gradovi imali čvrstu ovojnicu urbanosti, koja je već izdržala određene istorijske probe, tada ne bi bio dovoljan jedan rat, talasi izbeglica niti tranzicioni kalamburi, pa da se preobrate njegove urbane vrednosti. Poznato je da su tokom istorije, promenama znatno snažnijih pod-kulturunih invazija, odolevali upravo oni gradovi koji su imali „staru“ urbanu ovojnicu. Da takvo tlo u našim gradovima nije bilo dobro društveno pripremljeno, govori već i sama činjenica da su se raspali upravo po kulturnim šavovima. To će reći da oni homourbaniti koji su znatno davnije stekli gradske adrese, nisu uspeli da se množinom i kvalitetom izbore za očuvanje tih vrednosti. Nisu mogli jer ih ni kvalitetom ni brojčano nije bilo dovoljno.

Celokupan diskurs kulture antiurbanosti kao prakse tranzicijskih procesa u Srbiji nije moguć van saznanja o autarhičnoj raspodeli urbanih značenja. Srbija danas pokušava da funkcioniše sa nezgrapnim poluurbanim telom i Beogradom kao urbanim hidrocefalusom. Beograd je danas možda jedina markacija na putu na kom Srbija želi da bude prepoznata kao moderno, urbano društvo. Reč je o jedinoj srpskoj metropoli koja se i sama još uvek bori sa ruralnim reliktima, rasutim pre po njegovom duhovnom nego fizičkom prostoru. Da paradoks bude još veći, Beograd je možda jedini „urbani bedem“ spram nezaustavljivog procesa poseljačenja gradova u Srbiji. Njegova stamenost počiva, između ostalog, na petrifikovanim temeljima gradskog identiteta. Najveći deo ostalih gradskih naselja u Srbiji neprekidno pokušava da sa svog materijalnog i duhovnog bića otrese nataložene slojeve provincijalnosti. Ona oponašaju Beograd u svemu: pokušajima da se izdignu iznad turobne svakodnevice makar malenim krpicama etitnih sadržaja, pa do svakovrsnih oprostačenja. Međutim, za razliku od metropole, čiji urbani metabolizam ne mogu da nagrizu ni oprostačenja, u provinciji se ona lakše „primaju“, postaju očevidniji i dugotrajne oštećuju zatečene vrednosti.

\section{$* * *$}

Jednom prilikom smo naznačili kako je pitanje o povezanosti kulture, civilizacije i grada, ma koliko davno postavljeno, uvek iznova aktuelno. Živeći svoje živote, 
ispunjene potrebom da se prevlada ponekad nimalo poželjni oblici svakodnevnog

života, obični građani najčešće nisu u stanju da se posvećuju pitanjima svog pripadanja određenom društvu. To nije bilo moguće ni u starovekovnim društvima koje je istorija prepoznala kao "pragraditelje" gradskog načina života. Tu svakako i pre svega mislimo na grčki polis i građanina čiji je svet bio ispisan plemenitim značenjima demokratije, politike i učestvovanja u javnom životu. Svakodnevica ima svoj unutrašnji sadržaj i tumačenja koja dolaze spolja. Tako je manje-više sa svim društvenim pojavama koje pokušavamo analitički da obuhvatimo. Jasno je da pojave postoje same po sebi i za sebe a mnoge od njih su van pažnje analitičara društvene stvarnosti. To što one analitički nisu ,obrađene“, ne znači da snažno ne obeležavaju ukupan društveni život (Pušić 2005a).

Kada bi bilo moguće da se sagleda sva množina društvene misli o gradu, verovatno da bismo ugledali kako većina od njih u svom središtu ima kulturu; kao uslov i istovremeno kao posledicu koju su stvorili specifični oblici društvenog života. Istovremeno znamo da odgonetanje uzročno-posledičnih veza između grada i kulture gotovo da nema smisla jer je reč o conditio sine qua non svake sociološke analize urbane stvarnost. Samim tim ostaje pitanje o tome pod kojim uslovima bismo mogli da razumemo grad kao agens stvaranja kulture. Put do odgovora najverovatnije bi nas vodio pravcem kojim je išao i O. Špengler kada je tumačio kako se, kada i pod kojim uslovima jednače civilizacija i kultura, odnosno da je upravo grad ono što ih objedinjuje. Dakle, razumećemo da je grad agens posebnog oblika života koji vodi civilizovanosti. U smislu modernih zapadnih društava to bi moglo da se smesti i u kontekst vrednosti građanskih društava. U tom slučaju, pred nama stoji model unutar kog možemo da govorimo o određenim normama i vrednostima.

Pođemo li u pravcu traganja za značenjima urbane kulture kao mogućem ključu za odgovore o tome da li je ona objašnjavajuća ravan za razumevanje grada, neminovno ćemo se sresti sa mnogim istraživačima društvene stvarnosti (a ne samo sa sociolozima), koji su na taj put odavno krenuli. Ideja da se putem ili preko kulture objašnjavaju specifični društveni procesi i društveni život kao celina koja bi se mogla analitički objasniti, svakako je veoma stara. U svakom slučaju, ona ne pripada, kako se to ponekad smatra, modernim vremenima i pokušajima da se po svaku cenu objasne svi tokovi društvenog života. Ako bismo pak bili skloni da idemo putem na kome se objašnjenja za pojedine oblike kulture nalaze u načinima društvene organizacije, tada 
bismo mogli da poverujemo kako se i urbana kultura javlja kao posledica jednog mega-procesa koji nam je poznat kao društvena organizacija. ${ }^{2}$ Kada bi grad i sa njim kultura (ako ih je uopšte moguće razlučiti) mogli da se "pročitaju" u jednostavnom ključu oblika društvene proizvodnje, tada bi se uništila i ideja da postoje varijeteti u gradskim kulturama unutar istih nacionalnih, državnih ili istorijsko-razvojnih odrednica. To bi značilo da suštinske razlike između Segedina i Novog Sada, pa čak i između Novog Sada i Niša, na primer, gotovo i ne postoje. Kako bi samo bilo jednostavno i neinteresantno da je tako!

U pokušajima da razumemo kakvi su potencijali urbane kulture u Vojvodini, ne bi li postavili osnovu za posmatranje procesa modernizacije unutar ove, za nas posebno interesantne društvene laboratorije, napisali smo kako urbana kultura sama za sebe ne postoji. „Ona postoji samo ukoliko postoji urbano društvo. Činjenica da takvo društvo postoji, otvara put ka razumevanju specifičnog oblika civilizacijske komunikacije koji se uobličava u i uz pomoć urbanog društva. Kako su urbana društva istorijska činjenica koja seže u starovekovne civilizacije, o njima nije moguće reći ništa novo što bi poduprlo našu potrebu da se razmatraju pojedina pitanja savremenih urbanih društava. Međutim, ova činjenica "daje za pravo" da se urbana kultura, koja predstavlja samu društvenu esenciju u karakterisanju civilizacija, uvek iznova problematizuje. Pri tome polazimo od razrešene dileme o jednačenju civilizacije i kulture. Kako kaže F. Brodel, civilizacija, to je predstava celog čovečanstva i civilizacije, rasuta u vremenu i prostoru. Osim toga, reč civilizacija nikada ne putuje sama: neizbežno je prati reč kultura, koja, međutim, nije njen prost dvojnik. On takođe razlikuje jedninu i množinu reči kultura i otud tvrdi da je civilizacija skup kulturnih crta, pojava. I mi odatle polazimo; ukoliko želimo da imenujemo civilizaciju koja se stvara na prostorima kojima pripadamo, otvorićemo njen kulturni sadržaj, ne bi li je tako bolje razumeli i konačno utvrdili njene specifičnosti” (Pušić 2003: 9).

2 Kritikujući stanovišta L. Virta o posebnostima urbane kulture, M. Kastels je upravo posegnuo za argumentima koji objašnjavaju kako je svaki adjektiv koji ide uz pojašnjenje pojma i sadržaja kulture, ustvari zadat društvenom organizacijom. Naravno, moglo bi, ali ne i obavezno, i tako da bude. Za mnoge stare kulture, recimo u istorijskom starom veku, znano je da su imali gradske sdaržaje koji ni slučajno nisu bili sporedni u definisanju ukupnog društvenog profila, ali ne možemo uvek, sem u herodotovskom smislu, da saznajemo kakva je zapravo bila celina društvene organizacije. Materijalna i društvena arheologija ponekad nemaju iste nalaze o određenim vremenima, što je i prirodno. Njihov susret ponekad biva obeležen nizom kontroverzi. Imajući u vidu prirodu ovih nauka, njihove metodološke aparate i analitičke instrumente, ne nalazimo da je to neobično. 
Takođe smo prepoznali da je sadržaj urbane kulture rezultat procesa dugog trajanja u čijem se središtu nalaze temeljna obeležja konkretnog društva. Ta obeležja mogu se razumeti i kao svojevrstan društveni ambijent. Međutim, društveni ambijent sam po sebi ne postoji, već ga "grade" preduslovi političke, ekonomske, kulturno-genetičke i ekološke prirode. Svaki od ovih preduslova postavio je određene okvire unutar kojih se odvijao svakoliki društveni život. Kako ni u jednom od njih nije napravljen ozbiljan, analitički i objektivan bilans društvenih postignuća u Srbiji, moguće je, makar na fenomenološkom nivou, da se prepoznaju mnogi oblici antiurbane kulture. Jer, ako je put ka urbanom istovremeno i put ka modernom građanskom društvu, tada mozaik političkih, ekonomskih i ekoloških okolnosti (u sociološkom smislu reči) pruža sliku o životu srpskog društva i pokazuje da se Srbija nalazi na stranputici. Oprostačena politika u kojoj se ne prepoznaje opšti interes i racionalno u smislu očuvanja građanskih vrednosti, ekonomska nesolidnost u upravljanju na lokalnom, regionalnom i nacionalnom nivou i socijalno-ekološko približavanje sela i grada ali samo u jednom pravcu - poseljačenju gradova - govore o nemogućnosti puta u urbano društvo. Ozbiljni društveni poremećaji, traže ozbiljnu dijagnozu a ona ozbiljno lečenje. Na žalost, Srbija je danas u vrtlogu društvene stihije.

\section{LITERATURA}

Margalit, Avišaj (1998). Pristojno društvo. Beograd: B92.

Pušić, Ljubinko (1997). Grad, društvo, prostor: sociologija grada. Beograd: Zavod za udžbenike i nastavna sredstva.

Pušić, Ljubinko (2000). "Srbija između ruralnog i urbanog društva: jedan pogled". Sociologija, Vol. XLII, 3: 437-450.

Pušić, Ljubinko (priredio), (2003). Urbana kultura: osnova održive multikulturalnosti. Novi Sad: Specijalističke Akademske Studije i Centar za sociološka istraživanja Filozofskog fakulteta.

Pušić, Ljubinko (2005). “Gradovi kao kradena roba”, Limesplus. 2: 111-119.

Pušić, Ljubinko (2005a), "Urban Life as Everyday Life: Cultural Context", International Association for Southeast European Anthropology, $3^{\text {rd }}$ Conference Urban Life and Culture in Southeastern Europe. 
Šorske, Karl E. (2008). „Ideja o gradu u evropskoj misli - od Voltera do Špenglera“, Polja. 453: 57-70.

Štrbac, Lorna, (2009). <http://www.nspm.rs/kuda-ide-srbija/smisaoantievropskih-sila-u-srbiji.html?alphabet $=1>$.

Tartalja, Ivo (1989). Beograd XXI veka. Beograd: SKZ.

Ljubinko Pušić

PRACTICE OF TRANSITIONAL PROCESSES IN SERBIA AS CULTURE OF ANTIURBANITY

\section{Summary}

At least during last two decades it has been clear that Serbia is on a path of antimodernization. Absence of a clear social concept which would lead to a modern, democratic and civil country can be documented and traced at several different levels. This paper discusses causes and consequences of some anti-urban processes, which represent the practice of country's latter transitional path: urbanization is at first place. The creative possibilities and the dichotomy urban-rural are also being discussed, as union of two cultural models. The theoretical and practical platform, on which the paper stands, is based on the attitude that culture of antiurbanity appears in Serbia as the practice of transitional processes.

Key words: city, urbanity, culture, transition, urbanization. 